\title{
KÜRESEL YÜZEYLER ETRAFINDA NANO AKIŞKANLARDA HAVUZ KAYNAMA ISI TRANSFERİNİN DENEYSEL İNCELENMESİ
}

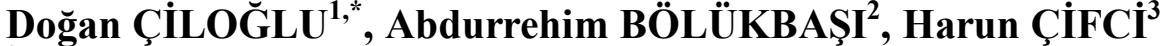 \\ ${ }^{1}$ Atatürk Üniversitesi, Erzurum Meslek Yüksekokulu, Elektrik ve Enerji Bölümü, 25240, Erzurum \\ ${ }^{2}$ Atatürk Üniversitesi, Mühendislik Fakültesi, Makine Mühendisliği Bölümü, 25240, Erzurum \\ ${ }^{3}$ Harran Üniversitesi, Mühendislik Fakültesi, Makine Mühendisliği Bölümü, 63300, Şanlıurfa \\ dciloglu@atauni.edu.tr, aboluk@atauni.edu.tr, haruncifci@harran.edu.tr
}

(Geliş/Received: 24.11.2014; Kabul/Accepted: 14.05.2015)

\section{ÖZET}

$\mathrm{Bu}$ çalışmada, atmosfer basıncı altında ve doyma şartlarında nano akışkanlarla su verilerek soğutulan yüksek sıcaklıktaki küresel yüzeyler etrafında havuz kaynama isı transferi deneysel olarak incelenmiştir. Deneylerde $\% 0,01, \% 0,05$ ve $\% 0,1$ olmak üzere üç farklı hacimsel konsantrasyonda saf su esaslı silika, alümina, titania ve bakır oksit nano akışkanları kullanılmıştır. Bronz malzemeden yapılmış küresel test numunesi yüksek sıcaklıklara kadar 1sıtıldıktan sonra, doymuş şartlardaki nano akışkan süspansiyonlarına aniden daldırmıştır. Numuneye ait sıcaklık-zaman verileri ile soğuma eğrileri çizilmiş ve kaynama eğrileri elde edilmiştir. Deneysel sonuçlar, test numunesinin soğuma performansının nano akışkan tipine ve konsantrasyonuna bağlı olarak değiştiğini göstermiştir. İlk su verme testlerinde saf suya yakın değerler elde edilmesine rağmen, nano akışkanlarda tekrarlı testler ile soğuma süresinin önemli ölçüde kısaldığı görülmüştür. Bu etki nano partikül konsantrasyonuyla artmıştır. Özellikle silika nano akışkanı için tekrarlı su verme testleri ile film kaynama kaybolmuş ve kritik 1sı akısı önemli derecede artmıştır. Deneysel sonuçlar, ayrıca, çekirdek havuz kaynama 1sı transferinde tüm nano akışkanlar için önemli bir değişimin olmadığını göstermiştir. Sonuç olarak, nano akışkanlar ile su verme testleri sonrasında, test yüzeyi üzerinde biriken nano partiküllerin yüzeyin sslatabilirliğini artırdığı ve böylece kritik 1sı akısında artışa neden olduğu belirlenmiştir.

Anahtar Kelimeler: Isı transferi, havuz kaynama, nano akışkanlar, küresel yüzeyler

\section{EXPERIMENTAL INVESTIGATION OF POOL BOILING HEAT TRANSFER IN NANOFLUIDS AROUND SPHERICAL SURFACES}

\begin{abstract}
In this study, the pool boiling heat transfer around spherical surfaces with high temperature quenched by nanofluids at saturated conditions and under atmospheric pressure was experimentally investigated. In the experiments, pure water-based silica, alumina, titania and copper oxide nanofluids with three different volumetric particle concentrations $(0.01,0.05$ and $0.1 \%)$ were used. After the spherical test specimen made up off brass material was heated at high temperatures, it was suddenly plunged into the nanofluid suspensions at saturated conditions. Using the temperature-time data of the specimen, the cooling curves were drawn and the boiling curves were obtained. The experimental results showed that the cooling performance of test specimen depended on the type of nanofluids and nanoparticle concentration. In the first quenching tests, although the cooling trend were nearly identical to that in pure water, it was observed that the cooling time was considerably shortened with the repetition tests in nanofluids. This effect enhanced with the nanoparticle concentrations. For silica nanofluids, especially, the film boiling region vanished during the repetition tests and the critical heat flux dramatically increased. The experimental results also showed that a considerable change in nucleate pool boiling heat transfer was not observed for all nanofluids. Consequently, it was determined that the nanoparticles deposited on the test surface after the quenching tests by nanofluids increased the wettability and thus caused the increment in critical heat flux.
\end{abstract}

Keywords: Heat transfer, pool boiling, nanofluids, spherical surfaces 


\section{GİRIŞ (INTRODUCTION)}

Günümüzde, gelişen teknoloji ile beraber birçok sistem hem daha küçük boyutta hem de daha verimli çalışacak şekilde tasarlanmaktadır. Isı transferinin gerçekleştiği bu uygulamalarda sistem veriminin artışı iş yapan akışkanla doğrudan ilişkilidir. Geleneksel ısı transfer akışkanları, düşük termal özellikleri nedeniyle yeni nesil cihazlarda sistem verimlerini olumsuz yönde etkileyebilir. Araştırmacılar, nano akışkanların bu açığı kapatabileceğini vurgulamışlardır.

Nano akışkanlar, nano boyutlarındaki katı partiküllerin $(<100 \mathrm{~nm})$ su, yağ ve antifriz gibi geleneksel 1sı transfer akışkanlarına belirli oranlarda ilave edilmesi ile elde edilen yeni nesil isi transfer akışkanlarıdır [1]. Düşük partikül boyutu nedeniyle artan 1sı transfer yüzey alanı, yüksek termal iletkenlik, daha kararlı ve durağan süspansiyon, partiküller nedeniyle artan türbülans etkisi gibi özellikleri ile nano akışkanlar tıp, üretim ve otomotiv sektöründe, mikro-elektronik sistemlerin soğutulması ve isıtma havalandırma ve iklimlendirme sistemleri (HVAC) gibi birçok alanda araştırmacıların ilgisini çekmiştir.

Genellikle nano akışkanlar tek adım ve iki adım yöntemiyle hazırlanmaktadırlar. Tek adım yönteminde nano partiküller temel akışkan içerisinde üretilir ve böylece nano akışkan üretilmiş olur. İki adım yönteminde ise fiziksel veya kimyasal tekniklerle elde edilen nano partiküller belirli oranlarda temel akışkana ilave edilerek nano akışkanlar üretilmektedirler. $\mathrm{Bu}$ yöntemde süspansiyon kararlılığını artırmak ve partikül topaklanmasını önlemek için süspansiyona ultrasonik titreşim uygulamanın yanı sıra, $\mathrm{pH}$ ayarı ve seyreltici ilavesi de yapılabilmektedir. Nano akışkan üretiminde kullanılan nano partiküller genellikle, metal (gümüss, altın, bakır ve demir), metal oksit (alümina, bakır oksit, silica ve titania) ve metal olmayan (karbon nano tüpler) partiküllerdir.

Yüksek sıcaklıktaki katı malzemelerin bir sıvı içerisinde soğutulması işlemi "su verme" olarak tanımlanmaktadır. Su verme işlemine çeșitli endüstriyel uygulamalarda rastlamak mümkündür. Örneğin, çelik malzemeler 1sitıldıktan sonra su içerisinde hızlı veya yağ içerisinde yavaş bir şekilde soğutularak sertleştirilmektedir. Gıda sektöründe ise sıv1 karbondioksit (kuru buz) içerisinde soğutulmak suretiyle birçok yiyecek şoklanmaktadır. Diğer taraftan, su verme işlemi nükleer reaktörlerde soğutucu akışkanın azalması halinde meydana gelebilecek kazaların azaltılmasında önemli bir rol oynamaktadır [2]. Böyle bir reaktörde soğutucu akışkanın yetersiz kalması halinde yakıt sıcaklığı çok yüksek sıcaklıklara çıkabilir $\left(>1000^{\circ} \mathrm{C}\right)$. Bu durumda, yakıt sıcaklığını düşürmek için reaktör çekirdeğine soğuk su püskürten acil soğutma sistemi devreye girer. $\mathrm{Bu}$ soğutma işlemi, reaktör çekirdeğinden yukarı doğru yavaş bir şekilde ilerleyen ön soğutma işlemi ile gerçekleştirilir. Bir kaza durumunda ön soğutma hızı ve dolayısıyla yüksek yakıt sıcaklığı, yüzeydeki film kaynama 1sı transferine ve yüzeyin 1slatabilirliğine bağlıdır. Araştırmacılar, hafif su reaktörlerinde soğutma suyu içerisinde nano boyutta partiküller ihtiva eden akışkanların (nano akışkan) kullanılması ile ön soğutma hızında ve dolayısıyla reaktör güvenliğinde belirgin bir artış sağlanacağını beklemektedirler [3].

Genel olarak, bir su verme işlemi süresince 1sı transfer miktarı, katı yüzey üzerinde 1sı transferini engelleyici kararlı bir buhar film tabakasiyla (film kaynama bölgesi) sinırlı kalmaktadır. Daha iyi 1sı transferi için birçok uygulamada film kaynamadan çekirdek kaynamaya hızlı bir geçişin olması istenir. Nano akışkanların bu geçişi hızlandıracağı ve 1sı transferini iyileştireceği düşünülmektedir [2]. Literatürde su verme işlemi üzerine yapılan çalışmalarda genellikle silindirik veya küresel malzemeler kullanılmıștır. Ancak elde edilen sonuçlar birbirleriyle çelişmektedir. Kim vd. (2009), nano akışkanlarla su verilerek soğutulan çelik ve zirkonyum alaşımlı küreler kullanmışlardır. Çalışmada, art arda yapılan su verme işlemleri sonucunda küre yüzey üzerine nano partiküllerin biriktiği gözlenmiştir. Yazarlar, nano partikül kaplı küre yüzeylerde soğuma performansının ve kritik 1Sı akısının (CHF) önemli ölçüde arttığını belirlemişlerdir [2]. Park vd. (2004), yüksek sıcaklıkta bir paslanmaz çelik kürenin soğuması üzerine yaptıkları çalışmada, su esaslı $\mathrm{Al}_{2} \mathrm{O}_{3}$ nano akışkan kullanmışlardır. Araştırmacılar saf su ile karşılaştırıldığında nano akışkanlar için daha düşük film kaynama 1Sı transferi katsayıları elde etmişlerdir [4].

Lotfi ve Shafii (2009), yüksek sıcaklıkta gümüş küre etrafında nano akışkanlarla su verme sürecini incelemişlerdir. Saf su ile karşılaştırıldığında, nano akışkanların su verme performansını ve kaynama 1sı transfer katsayısını düşürdüğünü gözlemiş̧lerdir [5]. Ciloglu ve Bolukbasi (2011) tarafindan yapılan çalışmada, yüksek sıcaklıkta bronz silindirler su esaslı nano akışkanlarda su verilerek soğutulmuş ve soğuma davranışı incelenmiş̧ir. Nano akışkanlarda tekrarlı su verme işlemlerinde soğuma süresinin kısaldığını ve CHF değerinde önemli bir artış rapor etmişlerdir [6]. Habibi vd. (2014), su esaslı çok katmanlı karbon nanotüp (MWCNT) akışkanı kullanarak gümüş silindirler etrafinda su verme performansinı incelemişlerdir. Nano akışkan kullanılması durumunda daha düşük CHF değerleri elde edilmiştir. Ayrıca, tekrarlı su verme testleri sonucunda, soğuma süresinin hem saf suda hem de CNT nano akışkanında kısaldığını açıklamışlardır [7]. Yukarıdaki çalışmalarda araştırmacılar, deneyler süresince 1sıtma yüzeyinde biriken nano partiküllerin su verme davranışı üzerine önemli bir etkisinin olduğunu vurgulamışlardır. 
Bu çalışmada, nano akışkanlarda havuz kaynama 1sı transferi deneysel olarak incelenmiştir. Silika $\left(\mathrm{SiO}_{2}\right)$, alümina $\left(\mathrm{Al}_{2} \mathrm{O}_{3}\right)$, titania $\left(\mathrm{TiO}_{2}\right)$ ve bakır oksit $(\mathrm{CuO})$ nano partikülleri nano akışkan hazırlanmasında kullanılmıştır. \%0,01, \%0,05 ve \%0,1 olmak üzere üç farklı hacimsel konsantrasyonda saf su esaslı nano akışkan süspansiyonları hazırlanmıştır. Bronz malzemeden yapılmış ve yüksek sıcaklıklara kadar 1sitılan küresel test numunesi atmosfer basinci altında doymuş şartlardaki nano akışkan süspansiyonlarına daldırılmıştır. Numuneye ait sıcaklık-zaman verileri kaydedilerek soğuma eğrileri çizilmiştir. Kaynama eğrileri "Toplam kütle yaklaşımı (Lumped) metodu" ile elde edilmiştir. Kaynama 1sı transferi üzerine nano partikül tipi ve konsantrasyonun etkileri araştırılmıştır.

\section{MALZEME VE YÖNTEM (MATERIALS AND METHOD)}

\subsection{Nano Akışkanların Hazırlanması (Preparation of Nanofluids)}

Bu çalışmada nano akışkan hazırlanması için iki-adım yöntemi kullanılmıştır. Nano partiküllerin hacimsel konsantrasyonu $(\varnothing)$ ve gerekli nano partikül miktarı $\left(\mathrm{m}_{\mathrm{P}}\right)$ aşağıdaki bağıntılar kullanılarak hesaplanmıştır.

$\emptyset=\frac{\mathrm{V}_{\mathrm{P}}}{\mathrm{V}_{\mathrm{T}}}$

$\mathrm{m}_{\mathrm{P}}=\rho_{\mathrm{P}} \mathrm{V}_{\mathrm{P}}$

Burada, $V_{\mathrm{P}}, \mathrm{V}_{\mathrm{T}}$ ve $\rho_{\mathrm{P}}$, sirasıyla, partikül hacmi, süspansiyonun toplam hacmi ve nano partikülün yoğunluğudur. Ticari bir firmadan (NanoAmor@) Huston, TX, USA) satın alınan silika, alumina, titania ve bakır oksit nano partikülleri kullanılarak üç farklı hacimsel konsantrasyonda $(\% 0,1, \% 0,05$ ve $\% 0,01)$ saf su esaslı nano akışkan süspansiyonları hazırlanmıştır. Kullanılan nano partiküllerin özellikleri Tablo 1'de verilmiştir.

Elde edilen nano akışkan süspansiyonları oda sıcaklığında 10 dakika manyetik karıştırıcıda karıştırıldıktan sonra her deney öncesinde olası partikül topaklanmasını önlemek amacıyla yaklaşık 2 saat ultrasonic titreşime maruz bırakılmıştır. Her bir nano akışkan süspansiyonu deneyden hemen önce hazırlandığı ve kaynama süresince süspansiyon sürekli olarak karıştığ 1 için yaklaşık 1 saatlik deney boyunca süspansiyonlarda çökme gözlenmemiştir.

\subsection{Deney Düzeneği ve Test Numunesi (Experimental} Setup and Test Specimen)

Deney düzeneğine ait şematik resim Şekil 1(a)'da gösterilmiştir. Deney düzeneği temelde pnömatik piston, firın, kaynama kabı ve ölçme-kontrol ünitesinden oluşmaktadır. Test numunesini, 240 mm'lik bir strok uzunluğuna sahip firın ve kaynama kabı arasındaki mesafede hareket ettirmek için 0-10 bar basınç aralıklarında çalışan bir pnömatik piston kullanılmıştır. Test numunesini isıtmak için etrafi taş yünü ile izole edilmiş $400 \mathrm{~mm}$ çapında $200 \mathrm{~mm}$ yüksekliğinde ve $1000^{\circ} \mathrm{C}$ sicaklığa ulaşabilen silindirik bir firın kullanılmıştır. Fırın iç sıcaklığı bir K-tipi termokupul kullanılarak ölçülmüştür. Numune, oda sıcaklığından $600^{\circ} \mathrm{C}$ sıcaklığa yaklaşık 25 dakikada ulaşmıştır. Kaynama kabı $10 \mathrm{~mm}$ çapında $200 \mathrm{~mm}$ yüksekliğindeki Pyrex camdan imal edilmiştir. Kaynama kabı içerisinde akışkan sıcaklığını ölçmek için 2 adet K-tipi termokupul bulunmaktadır. Kaynama kabı "Yellow Line" marka MSH Basic model harici bir 1sitıcı (400W) üzerine yerleştirilmiştir. Bu isıtıcı kullanılarak saf su ve nano akışkan süspansiyonları yaklaşık 30 dakikada doyma sıcaklığına getirilmiştir. Sicaklık ölçümleri için kullanilan tüm termokupullar Advantech ISA PCL818HG marka data kartı aracılığı ile bir bilgisayar içerisine monte edilmiş veri toplama ünitesine bağlanmıştır. Deneylerde sıcaklık ölçümleri için bir PCLD-8115 32-channel thermocouple amplifier kullanılmış ve Genie Software programı ile veriler depolanmıştır.

Şekil 1(b)'de $20 \mathrm{~mm}$ çapında pirinç malzemeden yapılmış silindirik test numunesi gösterilmektedir. Numune merkezinden K-tipi termokupul (Ø1,5x50 $\mathrm{mm}$ ) ile sıcaklık ölçümü için $2 \mathrm{~mm}$ çapında delik açılmıştır. Sıcaklık ölçümündeki belirsizlik $\pm 0,1^{\circ} \mathrm{C}$ 'dir. Deney numunesi mekanik olarak destek çubuğuna bağlanmıştır. Destek çubuğu iyi bir şekilde yataklandığı için deney esnasında kaynamayı etkileyebilecek olası bir titreşim minimize edilmiştir.

\subsection{Deneyin Yapılışı (Experimental Procedure)}

Hazırlanan nano akışkan süspansiyonları kaynama kabına aktarılarak kaynama sıcaklığına kadar 1sitılırken, diğer tarafta deney numunesi de firında $600^{\circ} \mathrm{C}^{\prime}$ ye kadar 1sıtıldı. Bütün deneyler atmosfer basıncında $(\sim 0.83$ bar $)$ ve doymuş şartlarda $\left(92^{\circ} \mathrm{C}\right)$ yapild1.

Tablo 1. Nano partiküllerin termal özellikleri (Thermophysical properties of nanoparticles)

\begin{tabular}{lcccccc}
\hline Metal oksit & $\begin{array}{c}\text { Saflik } \\
(\%)\end{array}$ & $\begin{array}{c}\text { Partikül boyutu } \\
(\mathrm{nm})\end{array}$ & $\begin{array}{c}\rho \\
\left(\mathrm{kg} / \mathrm{m}^{3}\right)\end{array}$ & $\begin{array}{c}\mathrm{c}_{\mathrm{p}} \\
(\mathrm{J} / \mathrm{kgK})\end{array}$ & $\begin{array}{c}\mathrm{k} \\
(\mathrm{W} / \mathrm{mK})\end{array}$ & $\begin{array}{c}\text { SSA } \\
\left(\mathrm{m}^{2} / \mathrm{g}\right)\end{array}$ \\
\hline $\mathrm{SiO}_{2}$ & 99,5 & 20 & 2220 & 745 & 1,38 & $160 \pm 20$ \\
$\mathrm{Al}_{2} \mathrm{O}_{3}$ & 99,5 & $27-43$ & 3970 & 765 & 36 & 35 \\
$\mathrm{TiO}_{2}$ & $99+$ & $10-30$ & 4157 & 710 & 8,4 & $210 \pm 10$ \\
$\mathrm{CuO}$ & $99+$ & $30-50$ & 6310 & 535.6 & 76,5 & 13 \\
\hline
\end{tabular}




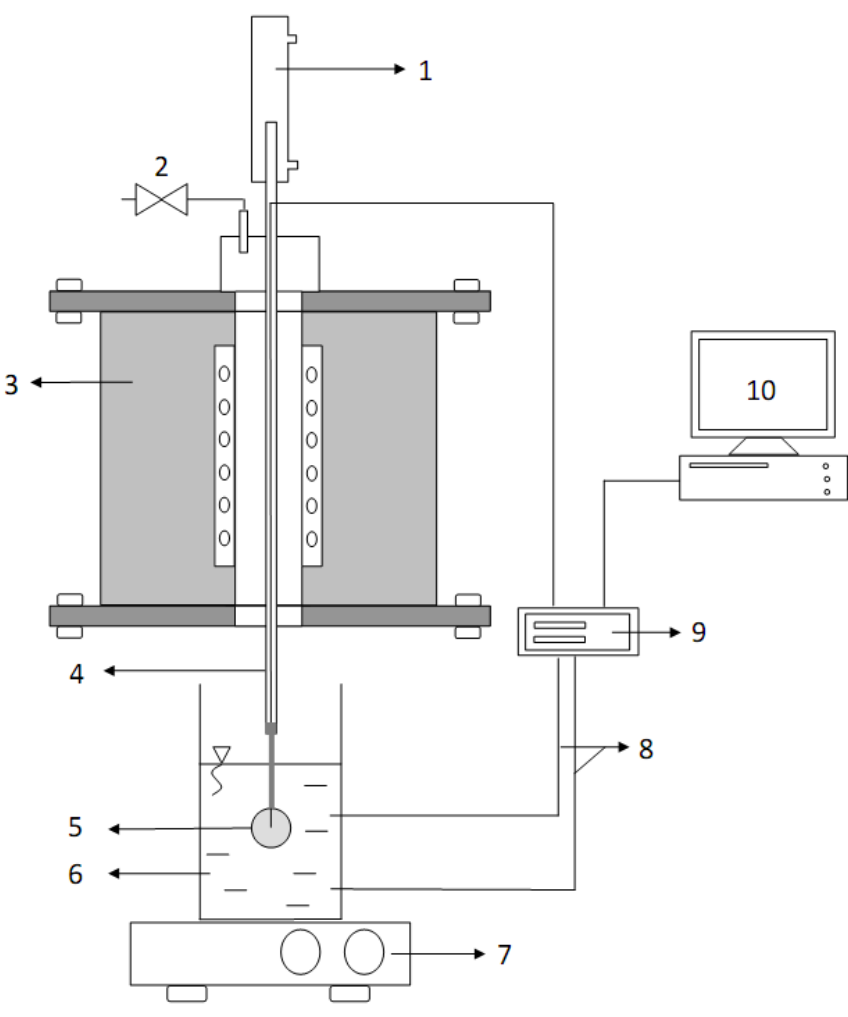

(a)

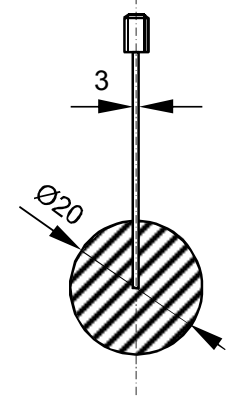

(b)

Şekil 1. (a) Deney düzeneğinin şematik görünüşü; (1) Pnömatik piston, (2) Azot $\left(\mathrm{N}_{2}\right)$ gazı girişi, (3) Fırın, (4) Numune destek kolu, (5) Test numunesi, (6) Kaynama kabı, (7) Isitic1, (8) K-tipi termokupul, (9) AnalogDijital Kart, (10) Bilgisayar ve (b) Deney numunesi ((a) Schematic of the experimental setup; 1- Pneumatic piston; 2 Nitrogen gas; 3- Furnace; 4- Support rod; 5- Specimen; 6- Quench pool; 7- Heater; 8- K-type thermocouple; 9- Analog-Digital Cart; 10 Computer and (b) the test specimen)

Isıtma işlemi süresince numune yüzeyinde oluşabilecek oksitlenmeyi azaltmak için firın içerisine Azot $\left(\mathrm{N}_{2}\right)$ gazı gönderildi. Numune $600^{\circ} \mathrm{C}$ sicaklığa ulaştığında ani bir şekilde doymuş akışkan havuzuna daldırıldı. Soğuma süresi boyunca numune merkezine yerleştirilen termokupul ile merkez sıcaklığı-zaman verileri kaydedildi. Test süresi, numune ile nano akışkan sıcaklığı 1sıl dengeye geldiğinde sona erdi. Elde edilen sicaklık-zaman verileri ile numuneye ait soğuma eğrileri çizildi. Bir önceki deneyde meydana gelebilecek yüzey değişimlerinin kaynama 1S1 transferi üzerine etkilerini belirlemek için, aynı numune tekrar firında 1sıtıldı ve tekrar nano akışkan havuzunda soğutuldu. Su verme işlemi $5 \mathrm{kez}$ tekrar edildi. Tekrarlı deneyler numune yüzeyi parlatılmadan ve aynı süspansiyon kullanılarak yapıldı. Nano akışkan süspansiyonu değiştirildiğinde numunenin yüzeyi de önce zımpara kâğıdı kullanılarak (1200 mesh) daha sonrasında alümina bulamacı ile mekanik olarak parlatild1.

\subsection{Kaynama Eğrilerinin Belirlenmesi (Determination of the Boiling Curves)}

Nano akışkan testleri öncesinde, doymuş şartlarda saf suda su verme testleri yapılmış ve elde edilen tipik soğuma eğrisi Şekil 2a'da verilmiştir. Numune sıcaklığı azaldıkça 1S1 transfer tiplerindeki geçişler şekil üzerinde belirtilmiş ve bunlar; (a) yüzeyde kararlı bir buhar filminin olduğu film kaynama bölgesini, (b) minimum 1sı akısı noktasını ve geçiş kaynama başlangıcını, (c) kritik 1sı akısı noktasını ve çekirdek kaynama başlangıcını, (d) doğal konveksiyon bölgesini göstermektedir [8].

Nano akışkan deneylerine temel oluşturması amacıyla saf su ile tekrarlı deneyler yapılmıştır. Elde edilen sonuçlar Şekil 2b'de görülmektedir. Şekil 2b'de tekrarlı deneylerde sadece geçiş kaynama ve çekirdek kaynama bölgesinde küçük sapmaların meydana geldiği görülmektedir. Bu sapmalara tekrarlı olarak 1sıtma ve soğutma işlemleri nedeniyle az da olsa yüzeyde meydana gelen oksitlenme neden olabilir. Elde edilen eğrilerden biri nano akışkan deneylerine temel oluşturması için seçilmiştir.

Soğuma eğrilerinden kaynama eğrilerini elde etmek için "Toplam kütle yaklaşımı (Lumped) metodu" kullanılmıştır. $\mathrm{Bu}$ yöntemde test numunesi içerisindeki sıcaklık gradyeni ihmal edilir. Bu şartın geçerliliği için Biot sayısı önemli bir parametredir. $\mathrm{Bi}<0,1$ olduğu durumda iletimle olan 1s1 transferi taşınım ile olan isı transferinden daha fazladır ve iç direnç ihmal edilebilir. $\mathrm{Bu}$ durum katı içindeki iç 
sıcaklık gradyeninin ihmal edilebilmesi anlamına gelir. $\mathrm{Bu}$ çalışmada Biot sayısı 0,04 olarak hesaplanmıştır. Böylece, bu varsayım kullanılarak deney numunesi için enerji dengesinden isı transfer katsayıları hesaplanabilir. Enerji dengesi aşağıdaki eşitlik ile ifade edilir.

$-h A\left(T-T_{d}\right)=\rho V c_{p} \frac{d T}{d t}$

burada, $\rho$ ve $c_{p}$ silindirin yoğunluğu ve özgül ısısıdır, $\mathrm{V}$ ve $A$ ise sırasıyla silindirin hacmi ve yüzey alanıdır. $\mathrm{dT} / \mathrm{dt}$, silindir merkezinden ölçülen sıcaklık değişimidir. Bu yaklaşım "Toplam kütle yaklaşımı" olarak bilinir ve bu analizden ortaya çıkacak hata $\% 5$ civarındadır [9]. Isı akıları ise;

$\dot{\mathrm{q}}=\mathrm{h}\left(\mathrm{T}_{\mathrm{y}}-\mathrm{T}_{\mathrm{d}}\right)$

eşitliği ile hesaplamıştır.
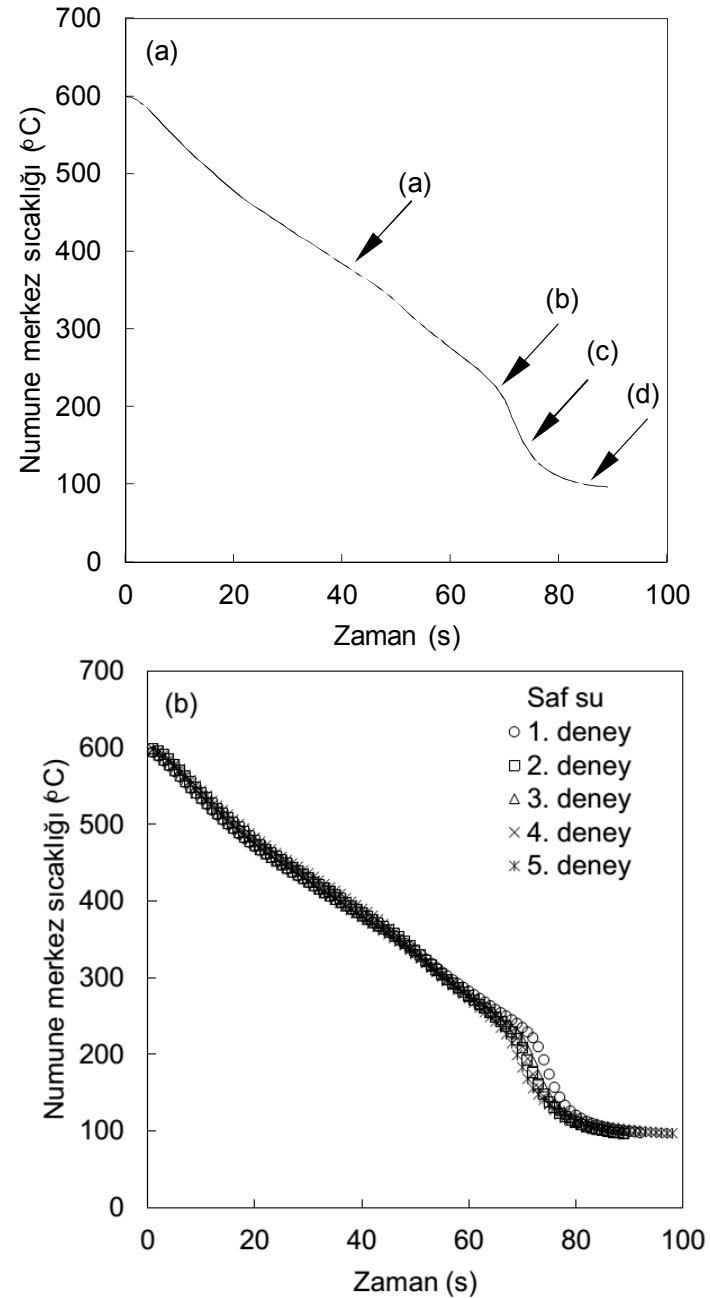

Şekil 2. Doymuş saf suda deney numunesine ait (a) zamana göre merkez sıcaklığı değişimi, (b) tekrarlı deneylerde elde edilen soğuma eğrileri ((a) The variations of center temperature vs time and (b) the cooling curves obtained in the repetitive tests of the test specimen at saturated pure water)

\subsection{Hata Analizi (Error Analysis)}

Eşitlik (3)'de verilen ölçülen parametrelerin hata miktarları Tablo 2'de verilmektedir. Değerleri literatürde kabul görmüş standart değerlerin ise hata miktarları göz önüne alınmamıştır [10]. Sonuç olarak, Buchanan ve Turner (1992) tarafindan önerilen hata analizi dikkate alınarak [11], 1sı transfer katsayısı ve 1S1 akıs1 için maksimum bağıl hata, sırasıyla, $\pm \% 3,8$ ve $\pm \% 3,9$ olarak hesaplanmıştır.

Tablo 2. Ölçülen parametrelerin hata miktarları (Uncertainties in the measured parameters)

\begin{tabular}{lll}
\hline Parametre $(\mathrm{u})$ & Ölçülen Değer & $\begin{array}{c}\text { Bağıl Hata Miktar } 1 \\
\left(\varepsilon_{\mathrm{u}}\right)\end{array}$ \\
\hline $\mathrm{V}\left(\mathrm{m}^{3}\right)$ & $4,19 \times 10^{-6}$ & 0,015 \\
$\mathrm{~A}\left(\mathrm{~m}^{2}\right)$ & $1,26 \times 10^{-3}$ & 0,01 \\
$\mathrm{t}(\mathrm{s})$ & 42 & 0,012 \\
$\mathrm{~T}^{*}$ & 0,0112 & $1,2 \times 10^{-3}$ \\
\hline
\end{tabular}

\section{BULGULAR ve TARTIŞMA (RESULTS and DISCUSSION)}

Şekil 3, 4 ve 5'te farklı hacimsel konsantrasyonlarda nano akışkanlara daldırılarak soğutulan numuneye ait soğuma eğrileri gösterilmektedir.

Şekil 3'te görüldüğü gibi, düşük partikül konsantrasyonlarında $(\% 0,01)$ soğuma eğrileri saf su ile benzer eğilimdedir. Ancak, Şekil 4 ve 5 'te partikül konsantrasyondaki artış ile ilk deneylerden sonra soğuma eğrilerindeki sapma miktarının da arttı̆̆ görülmektedir. $\mathrm{Bu}$ durum, numune yüzeyinin ilk deneylerde parlatılmış olduğundan dolayı, temiz yüzeye sahip test numunesinin soğuma davranış1 üzerine nano akışkanların az ya da hiç etkisinin olmadığını göstermektedir.

$\mathrm{Bu}$ sonuçlar Kim et al. (2009) tarafindan rapor edilen sonuçlarla uyum içerisindedir [2]. Tekrarlı su verme testleri sonucunda ise eğrilerdeki sola doğru kayma daha belirgin olmuştur. Böylece, film kaynama daha erken sona ermiş ve deney numunesi daha hızlı soğumuştur. Özellikle $\% 0,1$ partikül konsantrasyonunda silika nano akışkanı için (Şekil 5(a)) numune yüzeyinde oluşan kararlı buhar film tabakası tekrarlı deneylerde gözlenmemiştir. Sonuç olarak, nano akışkan tipi ve konsantrasyonu su verme davranışını önemli ölçüde etkilediği görülmektedir.

Şekil 5'te, en yüksek ve en düşük sapmanın sırasıyla, silika ve bakır oksit nano akışkanı için olduğu görülmektedir. Diğer taraftan, ilk su verme testlerinde test numunesi parlak yüzeye sahip olduğu için elde edilen soğuma eğrileri saf suyunkine oldukça yakındır. $\mathrm{Bu}$ durum, eğrilerdeki sapmanın nano akışkanın kendisinden dolayı değil de, yüzey üzerinde birikmiş partikül tabakası ile gerçekleşebileceğini göstermektedir. 

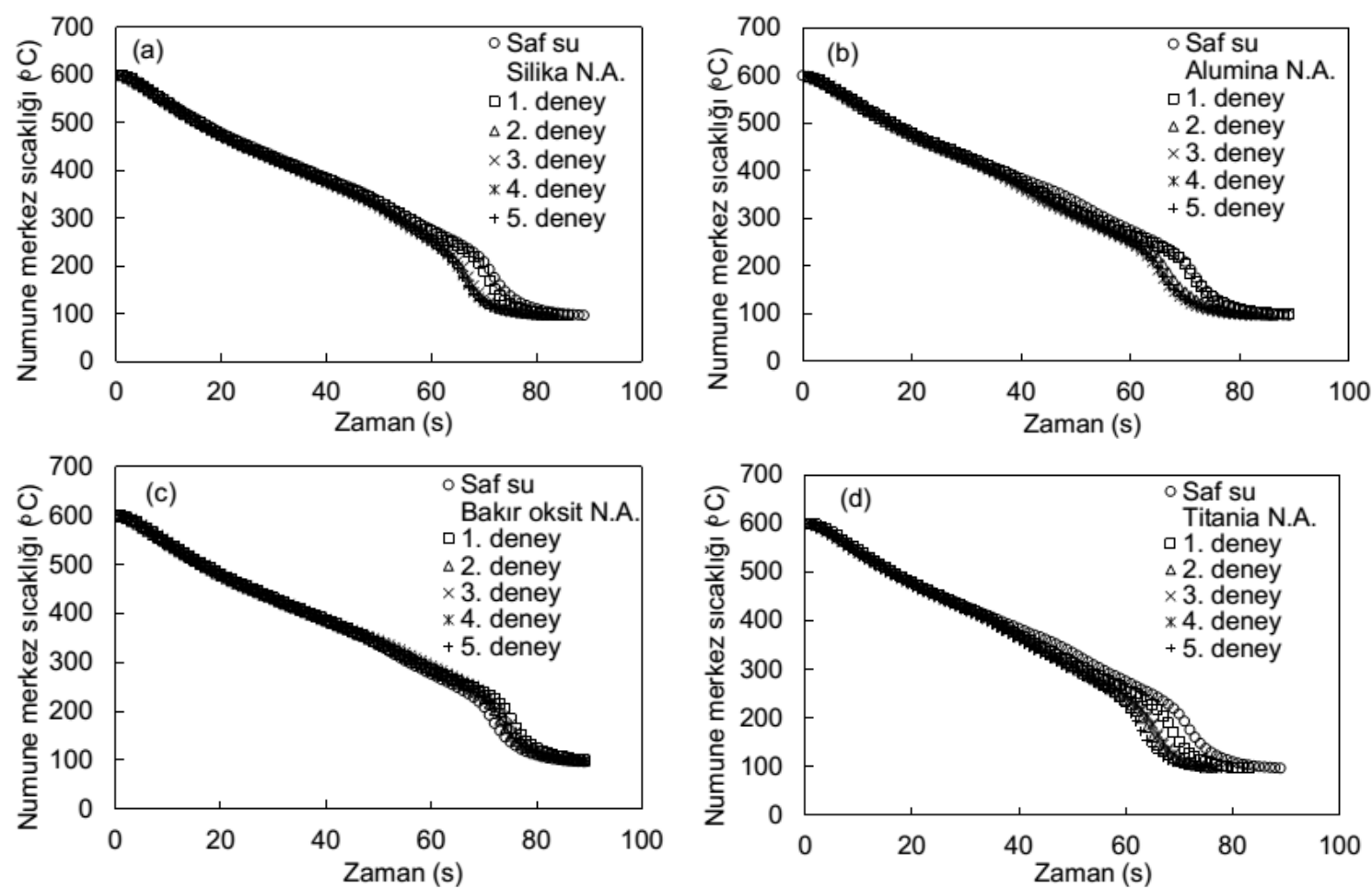

Şekil 3. Doymuş şartlarda \%0,01 partikül konsantrasyonunda nano akışkanlarda soğutulan deney numunesine ait sicaklık-zaman eğrileri (The temperature-time values in nanofluids ( $0.01 \mathrm{vol} . \%)$ at saturated conditions)
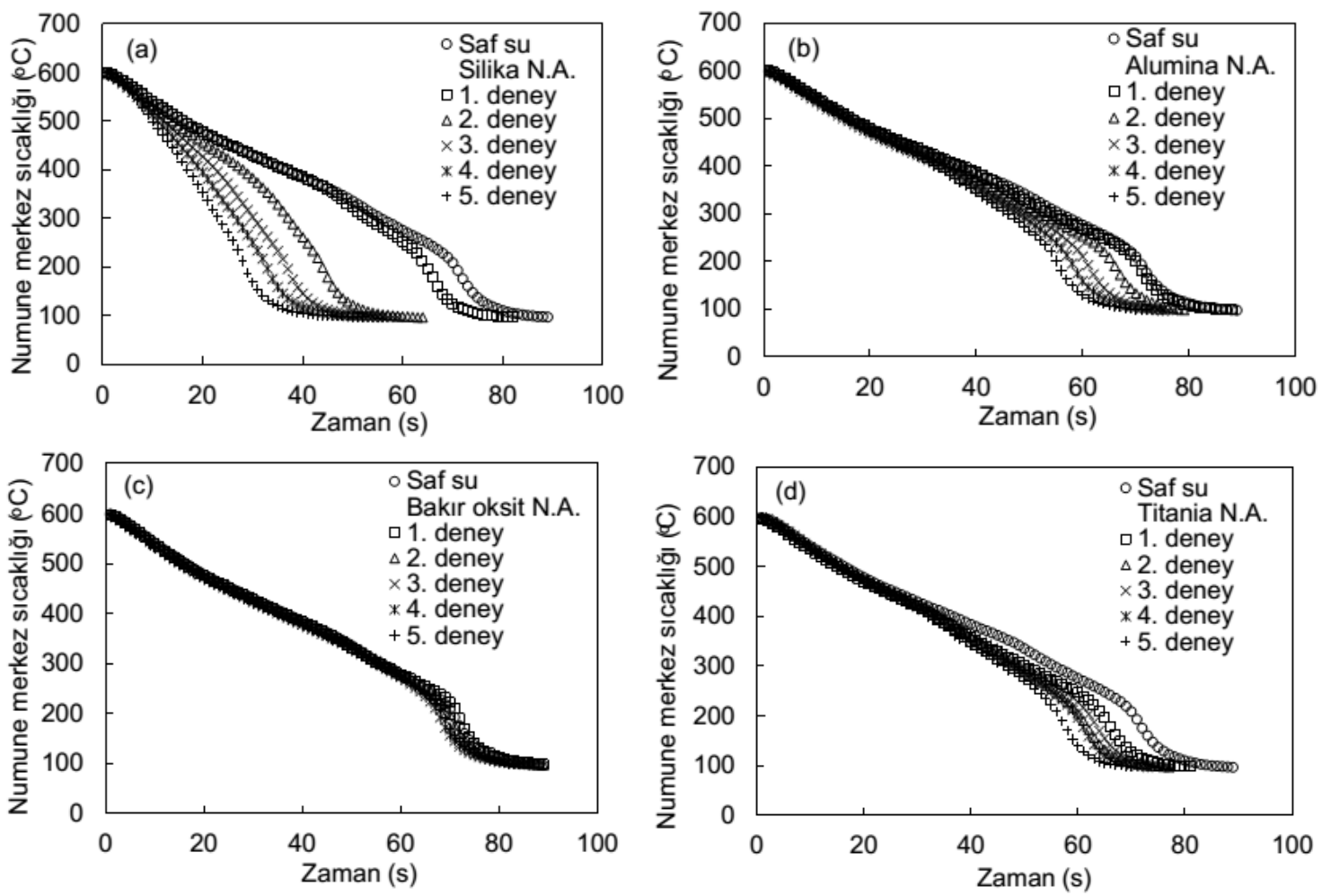

Şekil 4. Doymuş şartlarda \%0,05 partikül konsantrasyonunda nano akışkanlarda soğutulan deney numunesine ait sıcaklık-zaman eğrileri (The temperature-time values in nanofluids ( 0.05 vol.\%) at saturated conditions) 

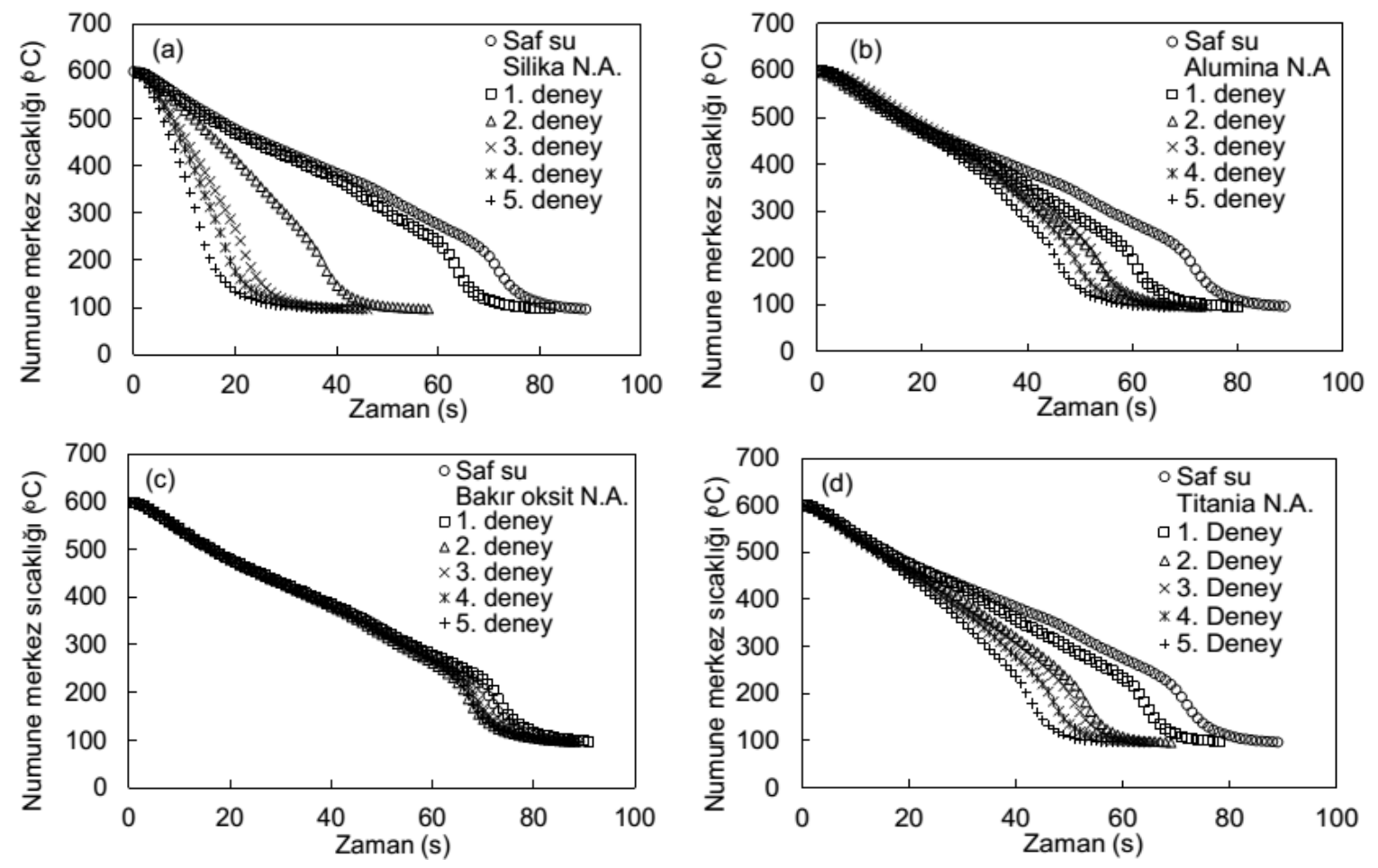

Şekil 5. Doymuş şartlarda \%0,1 partikül konsantrasyonunda nano akışkanlarda soğutulan deney numunesine ait sicaklık-zaman eğrileri (The temperature-time values in nanofluids ( 0.1 vol.\%) at saturated conditions)

Saf su ve \%0,1 nano partikül konsantrasyonuna sahip nano akışkanlar için kaynama eğrileri Şekil 6'da gösterilmektedir. İlk su verme deneylerinde tüm nano akışkanlarda film kaynama meydana gelmiştir. Ancak tekrarlı deneyler sonrasında özellikle \%0,1 silika nano akışkanı için, film kaynama gözlenmemiştir. Ayrıca, CHF değerlerinde diğer nano akışkanlarda aynı ya da az bir artış gözlenirken, silika nano akışkanında bu artış oldukça belirgin olmuş ve saf su ile karşılaştırıldığında tekrarlı su verme testleri sonrasında yaklaşık \%131 artış elde edilmiştir (Şekil 6(a)). Diğer taraftan, Şekil 6’da görüldüğü üzere, saf su ile karşılaştırıldığında, çekirdek kaynama 1sı transferi üzerinde nano akışkanların önemli bir etkisinin olmadığg görülmektedir.

Araştırmacılar, katı yüzey üzerinde biriken nano partiküllerin yüzeyin morfolojisini ve islatabilirliğini önemli ölçüde değiştirebileceği rapor etmişlerdir [1218]. Film kaynama bölgesinde sadece birkaç mikron kalınlığındaki buhar filmi, böylesi bir partikül birikmesinden etkilenebilir [19]. Film kaynamada sıvı-buhar ara yüzeyi sürekli dalgalıdır ve özellikle yüksek pürüzlülükte bir yüzeyde kısa süreli katı-sıvı temasları meydana gelebilir. Eğer yüzey oldukça ıslatan bir yüzey ise, sıvı yüzeye yapışır ve yayılır.
Bu durumda oluşan buhar kabarcıkları buhar filmini bozarak onun daha erken ve daha yüksek yüzey sıcaklıklarda kırılmasına neden olabilir.

Şekil 7'de test öncesi ve test sonrası numune yüzey fotoğrafları görülmektedir. Şekil 7'de görüldüğü gibi, özellikle silika deneyleri sonrasında numune yüzeyinde görünür ancak homojen olmayan bir nano partikül tabakası tespit edilmiş ve yüzey karakteristiklerinde önemli değişiklik meydana gelmiştir. Bu nedenle, soğuma eğrilerindeki sapmanın (erken soğumanın) temel sebebi, nano akıșkanlarla değil değişen yüzey karakteristikleriyle ilgilidir [2023]. Bu durumu doğrulamak için test numunesinin yüzeyinden temas açıları $(\theta)$ ölçülmüştür (KSV, Cam101 Scientific Inst.). Elde edilen sonuçlar Şekil 8'de gösterilmektedir. Şekil 8'de görüldüğü gibi, nano akışkan deneyleri sonrasında yüzey temas açısı önemli ölçüde azalmıştır. Bazı araştırmacılar da temas açılarında düşüş gözlemişlerdir ki bu durum yüzeydeki aktif buhar çekirdeklerinin sayısında düşüşe neden olmuştur [12,20,24-27]. Araştırmacılar düşük partikül konsantrasyonlarında bile $(<0.01 \mathrm{vol}$ \%) CHF değerinde \%250'ye varan önemli artışlar gözlemişlerdir [28-30]. Dolayısıyla bu artış nano akışkanların özellikleri ile açıklanamaz. CHF 
değeri temas açısıyla ters orantılı olarak değişmektedir ve bu nedenle CHF deki artışın sebebi artan 1slatabilirlik (düşük temas açısı) olabilir. Aşağıda gösterilen ve Wenzel tarafindan önerilen değiştirilmiş Young eşitliği bu durumu açıklamaktadır [31].

$$
\cos \theta=\frac{\gamma_{\mathrm{SV}}-\gamma_{\mathrm{SL}}}{\sigma} \mathrm{r}
$$

burada, $\gamma_{\mathrm{SV}}-\gamma_{\mathrm{SL}}$ adezyon gerilimi (yüzey geriliminin yatay bileşeni), $r$ ise pürüzlülük faktörüdür (aktif temas yüzey alanının toplam yüzey alanına oranı). Eşitlik 5'e göre, temas açısındaki azalma ile (veya yüksek 1slatabilirlik) adezyon gerilimi artar ve yüzeyde oluşacak buharlaşma gecikir ve böylece CHF değeri de artmaktadır [16].

CHF değerinde artışa neden olabilecek diğer bir etki ise k1lcallık etkisidir. Kim vd. (2007), yüzeydeki buhar kabarcıklarının altındaki kuru bölgeler kılcallık etkisi nedeniyle çevredeki akışkan ile ıslatılabilir ve böylece CHF'nin meydana gelmesi gecikir [32]. Ayrıca, Kim ve Kim (2007) tarafindan yapılan çalışmada da 1sıtma yüzeyinde oluşan nano partikül tabakasının neden olduğu kılcallık etkisi incelenmiştir [33]. Yazarlar, yüzeyde oluşan nano partikül tabakası nedeniyle iyileşen 1slatabilirlik ve kılcallık etkisi ile nano akışkanlarda daha yüksek CHF değerleri elde edildiğini belirtmişlerdir.

Literatürde bugüne kadar yapılan çalışmalarda, yüzey pürüzlülüğü, nano partikül boyutu, 1sıtıcı tipi ve yerleşimi, sistem basıncı, süspansiyonun kararlılığı ve ilave edilen seyrelticilerin etkisi gibi birçok parametrenin nano akışkanlarda CHF değerlerinde değişime neden olabileceği vurgulanmıştır. Ancak bu çalışmada yüzeyin 1slatabilirliği etkisi (wettability) üzerinde durulmuştur. Sonuç olarak, nano akışkanlarla su verilerek soğutulan test numunesinin değişen yüzey özellikleri kaynama davranışında meydana gelen değişikliğin temel sebebidir.
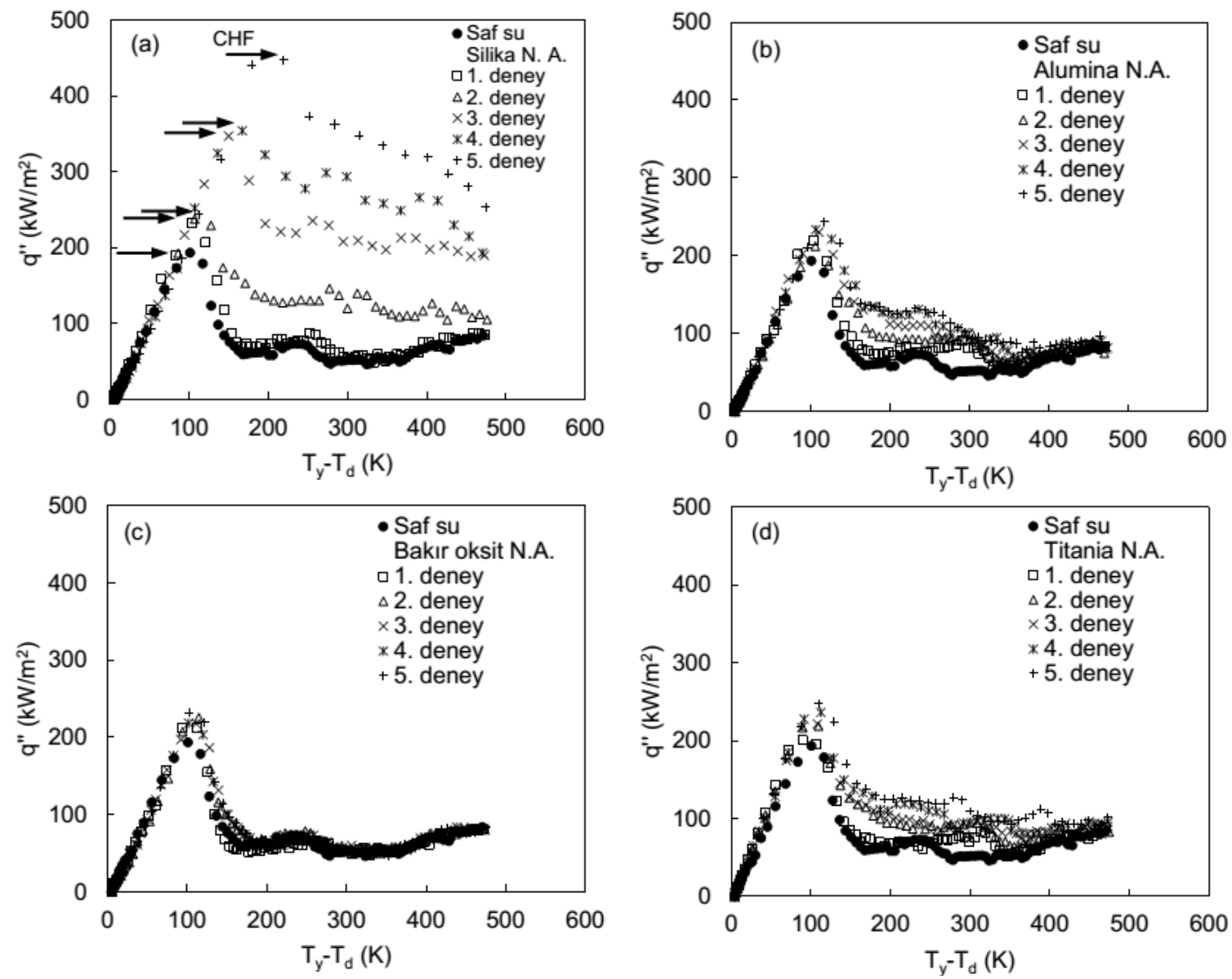

Şekil 6. Doymuş şartlarda \%0,1 partikül konsantrasyonunda nano akışkanlarda kaynama eğrileri (The characteristic boiling curves in nanofluids ( $0.1 \mathrm{vol} . \%)$ at saturated conditions) 

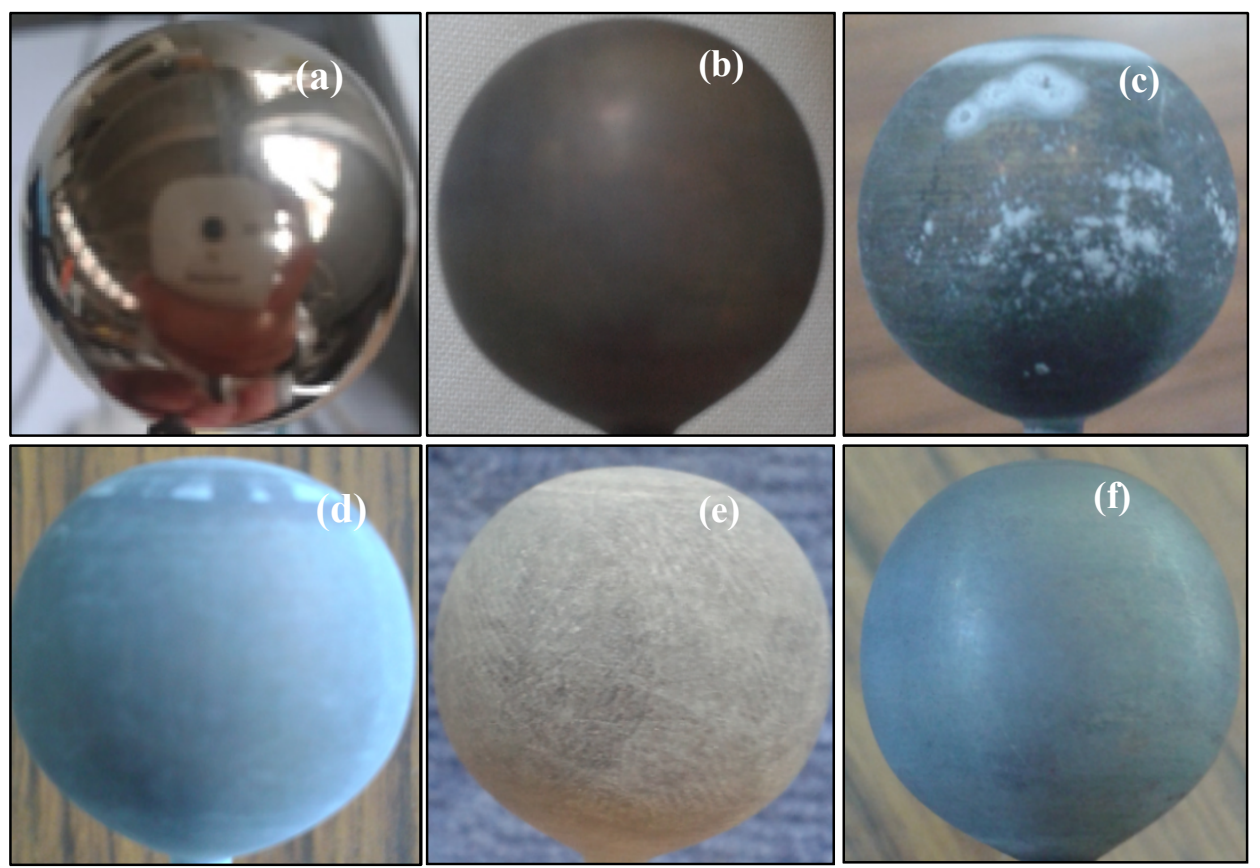

Şekil 7. (a) Test öncesi, (b) saf suda, (c) $\% 0,1 \mathrm{SiO}_{2}$ nano akışkanında, (d) $\% 0.1 \mathrm{Al}_{2} \mathrm{O}_{3}$ nano akışkanında, (e) $\% 0.1 \mathrm{TiO}_{2}$ nano akışkanında, (f) \%0.1 $\mathrm{CuO}$ nano akışkanında soğutulan deney numunesine ait yüzey resimleri (The photographs of the test specimen (a) before test, after quenched by (b) pure water, (c) $\mathrm{SiO}_{2}$, (d) $\mathrm{Al}_{2} \mathrm{O}_{3}$, (e) $\% 0.1 \mathrm{TiO}_{2}$ and (f) $\mathrm{CuO}$ nanofluids in 0.1 vol.\%)

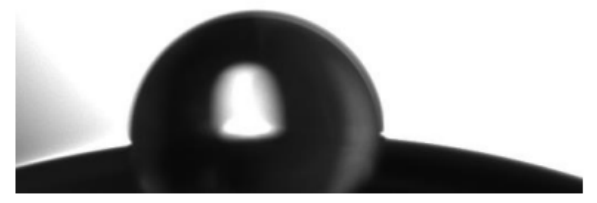

(a) temiz yüzey $\left(\theta=99,92^{\circ}\right)$

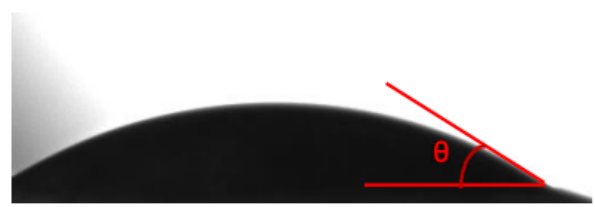

(c) $\% 0,05 \mathrm{SiO}_{2}$ nano akışkanında soğutulmuş yüzey $\left(\theta=32,30^{\circ}\right)$

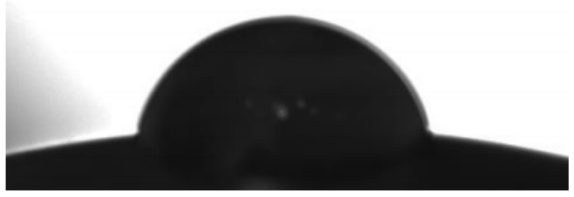

(b) su ile soğutulmuş yüzey $\left(\theta=81,85^{\circ}\right)$

(d) $\% 0,1 \mathrm{SiO}_{2}$ nano akışkanında soğutulmuş yüzey $\left(\theta=6,12^{\circ}\right)$

Şekil 8. Temas açıları (Contact angles)

\section{SONUÇLAR (CONCLUSIONS)}

Bu çalışmada, nano akışkanlarda havuz kaynama 1sı transfer karakteristikleri deneysel olarak incelenmiş̧ir. Deney numunesine ait su verme karakteristikleri kullanılan nano akışkan tipine ve nano partikül konsantrasyona oldukça bağlı olduğu görülmüştür.

Düşük partikül konsantrasyonlarında soğuma eğrilerinde önemli bir değişim olmamasına rağmen, yüksek konsantrasyonlarda, özellikle deney tekrarı ile, soğuma sürelerinde önemli kısalmalar gözlenmiştir. $\mathrm{Bu}$ durum özellikle silika nano akışkanı için daha belirgin olmuş ve film kaynama bölgesi kaybolmuştur. Nano partiküllerin deneyler sonunda homojen olmayan bir şekilde test numunesi üzerine biriktiği görülmüştür.

Kaynama eğrileri incelendiğinde en büyük değişimin silika nano akışkanı için olduğu görülmüştür. Tekrarlı deneyler sonunda silika nano akışkanı için CHF değerlerinde ciddi bir artış meydana gelmiştir. Yüzeyde biriken nano partiküllerin, yüzeyin 1slatabilirliğini artırdığı ve böylece CHF değerlerindeki artışın sebebi olduğu tespit edilmiştir. Genel olarak çekirdek kaynama isı transferinde önemli bir değişimin olmadığı gözlenmiştir. 


\section{SEMBOLLER (SYMBOLS)}

$\begin{array}{ll}\mathrm{A} & \text { Isı transfer yüzey alanı }\left(\mathrm{m}^{2}\right) \\ \mathrm{Bi} & \text { Biot sayısı } \\ \mathrm{c}_{\mathrm{p}} & \text { Sabit basınçta özgül } 1 \mathrm{~s} 1\left(\mathrm{~kJ} \cdot \mathrm{kg}^{-1} \cdot \mathrm{K}^{-1}\right) \\ \mathrm{h} & \text { Isı taşınım katsayısı }\left(\mathrm{kW} \cdot \mathrm{m}^{-2} \cdot \mathrm{K}^{-1}\right) \\ \mathrm{k} & \text { Isı iletim katsayısı }\left(\mathrm{W} \cdot \mathrm{m}^{-1} \cdot \mathrm{K}^{-1}\right) \\ \mathrm{m} & \text { Kütle }(\mathrm{kg}) \\ \dot{\mathrm{q}} & \text { Isı akısı }\left(\mathrm{kW} \cdot \mathrm{m}^{-2}\right) \\ \mathrm{r} & \text { Pürüzlülük faktörü } \\ \mathrm{SSA} & \text { Spesifik yüzey alanı }\left(\mathrm{m}^{2} \cdot \mathrm{g}^{-1}\right) \\ \mathrm{t} & \text { Zaman }(\mathrm{s}) \\ \mathrm{T} & \text { Sicaklık }\left({ }^{\circ} \mathrm{C}\right) \\ \mathrm{T} * & \text { Boyutsuz sıcaklık, }\left(\mathrm{T}-\mathrm{T}_{\mathrm{d}}\right) /\left(\mathrm{T}_{\mathrm{i}}-\mathrm{T}_{\mathrm{d}}\right) \\ \mathrm{V} & \text { Hacim }\left(\mathrm{m}^{3}\right) \\ \rho & \text { Yoğunluk }\left(\mathrm{kg} \cdot \mathrm{m}^{-3}\right) \\ \sigma & \text { Yüzey gerilmesi }\left(\mathrm{N} \cdot \mathrm{m}^{-1}\right) \\ \theta & \text { Temas açıs } \\ \varnothing & \text { Hacimsel partikül oranı } \\ \gamma & \text { Yüzey enerjisi }\left(\mathrm{N} \cdot \mathrm{m}^{-1}\right)\end{array}$

\section{KISALTMALAR (ABBREVIATIONS)}

$\begin{array}{ll}\text { d } & \text { Doyma değeri } \\ \text { P } & \text { Partikül } \\ \text { SL } & \text { Kat1-S1v1 } \\ \text { SV } & \text { Kat1-buhar } \\ \text { T } & \text { Toplam } \\ \text { y } & \text { Yüzey }\end{array}$

\section{TEŞEKKÜR (ACKNOWLEDGMENT)}

$\mathrm{Bu}$ çalışmaya maddi destek veren Atatürk Üniversitesi Bilimsel Araştırma Komisyonuna (Proje No: BAP- 2012/490) teşekkür ederiz.

\section{KAYNAKLAR (REFERENCES)}

1. Choi, S.U.S., "Enhancing thermal conductivity of fluids with nanoparticles", in: D.A. Siginer, H.P. Wang (Eds.), Developments and Applications of Non-Newtonian Flows, FED-vol. 231/MD-vol. 66, ASME, New York, 99-105, 1995.

2. Kim, H., DeWitt, G., McKrell, T., Buongiorno, J. ve $\mathrm{Hu}, \mathrm{L} . \mathrm{W}$., "On the quenching of steel and zircaloy spheres in water-based nanofluids with alumina, silica and diamond nanoparticles", International Journal of Multiphase Flow, Cilt 35, 427-438, 2009.

3. Kim, H., Buongiorno, J., Hu, L.W. ve McKrell, T., 2010. Nanoparticle deposition effects on the minimum heat flux point and quench front speed during quenching in water-based alumina nanofluids, International Journal of Heat and Mass Transfer, Cilt 53, 1542-1553.

4. Park, H.S., Shiferaw, D., Sehgal, B.R., Kim, D.K. ve Muhammed, M., "Film boiling heat transfer on a high temperature sphere in nanofluid", In: Proceedings of ASME HT/FED 2004, Cilt 4, 469-476, 2004.
5. Lotfi, H. ve Shafii, M.B., "Boiling heat transfer on a high temperature silver sphere in nanofluid", International Journal of Thermal Sciences, Cilt 48, No 12, 2215-2220, 2009.

6. Ciloglu, D. ve Bolukbasi, A., "The quenching behavior of aqueous nanofluids around rods with high temperature", Nuclear Engineering and Design, Cilt 241, No 7, 2519-2527, 2011.

7. Habibi, K.H., Saboonchi, A. ve Shafii, M.B., "The quenching of silver rod in boiling carbon nano tube-water nanofluid", International Journal of Thermal Sciences, Cilt 75, 95-104, 2014.

8. Jeschar, R., Spect, E. ve Heidt, V., “An analytical model for free convection film boiling on immersed solids", Chem. Eng. and Proc., Cilt 31, 137-146, 1992.

9. Incropera, F.P. ve DeWitt, D.P., Fundamentals of Heat and Mass Transfer, 4th ed., John Wiley and Sons, New York, A.B.D., 1996.

10. Yesilata, B., "A simple experimental method for determining natural convection heat transfer coefficient in liquids", Termodinamik, Cilt 146, 94-102, 2004.

11. Buchanan, J.L. ve Turner, P.R., Numerical Methods and Analysis, McGraw-Hill, New York, A.B.D., 1992.

12. Shahmoradi,. Z., Etesami, N. ve Esfahany, M.N., "Pool boiling characteristics of nanofluid on flat plate based on heater surface analysis", Int. Communications in Heat and Mass Transfer, Cilt 47, 113-120, 2013.

13. Sakashita, H., "CHF and near-wall boiling behaviors in pool boiling of water on a heating surface coated with nanoparticles", Int. J. Heat Mass Transf., Cilt 55, 7312-7320, 2012.

14. Kathiravan, R., Kumar, R., Gupta, A. ve Chandra, R., "Preparation and pool boiling characteristics of copper nanofluids over a flat plate heater", Int. J. Heat Mass Transf., Cilt 53, 1673-1681, 2010.

15. Kim, S.J., Bang, I. C., Buongiorno, J. ve Hu, L.W., "Surface wettability change during pool boiling of nanofluids and its effect on critical heat flux", Int. J. Heat Mass Transfer, Cilt 50, 41054116, 2007.

16. Bang., I.C. ve Chang, S.H., "Boiling heat transfer performance and phenomena of $\mathrm{Al}_{2} \mathrm{O}_{3}$-water nano-fluids from a plain surface in a pool", Int. J. Heat Mass Transfer, Cilt 48, 2407-2419, 2005.

17. Vassallo, P., Kumar, R. ve D'Amico, S., "Pool boiling heat transfer experiments in silica-water nano-fluids", Int. J. Heat Mass Transf., Cilt 47, No 2, 407-411, 2004.

18. Das, S.K., Putra, N. ve Roetzel, W., "Pool boiling characteristics of nanofluid", Int. J. Heat Mass Transf., Cilt 46, 851-862, 2003.

19. Park, H.S., Shiferaw, D., Sehgal, B.R., Kim, D.K. ve Muhammed, M., "Film boiling heat transfer 
on a high temperature sphere in nanofluid", in: Proceedings of 2004 ASME Heat Transfer/Fluids Engineering Summer Conference, Charlotte, NC, 1-8, 2004.

20. Golubovic, M.N., Hettiarachchi, H.D.M., Worek, W.M. ve Minkowycz, W.J., "Nanofluids and critical heat flux, experimental and analytical study", Appl. Therm. Eng., Cilt 29, 1281-1288, 2009.

21. Stutz, B., Morceli, C.H.S., Silva, M.F., Cioulachtjian, S. ve Bonjour, J., "Influence of nanoparticle surface coating on pool boiling", Exp. Thermal Fluid Sci., Cilt 35, 1239-1249, 2011.

22. Wen, D., Corr, M., Hu, X. ve Lin, G., "Boiling heat transfer of nanofluids: the effect of heating surface modification", Int. J. of Therm. Sci., Cilt 50, 480-485, 2011.

23. Mourgues, A., Virginie, H., Muller, T. ve Marylise, C.C., "Boiling behaviors and critical heat flux on a horizontal and vertical plate in saturated pool boiling with and without $\mathrm{ZnO}$ nanofluid", Int. J. Heat Mass Transfer, Cilt 57, No 2, 595-607, 2013.

24. Coursey, J.S. ve Kim, J., "Nanofluid boiling: the effect of surface wettability", Int. J. Heat Mass Transfer, Cilt 29, 1577-1585, 2008.

25. Kim, H. ve Kim, M., "Experimental study of the characteristics and mechanism of pool boiling CHF enhancement using nanofluids", Heat and Mass Transfer, Cilt 45, 991-998, 2009.
26. Truong, B., Hu, L.W., Buongiorno, J. ve McKrell, T., "Modification of sandblasted plate heaters using nanofluids to enhance pool boiling critical heat flux", Int. J. Heat Mass Transf., Cilt 53, 85-94, 2010.

27. Ahn, H.S. ve Kim, M.H., "The boiling phenomenon of alumina nanofluid near critical heat flux", Int. J. Heat Mass Transf., Cilt 62, 718-728, 2013.

28. Kathiravan, R., Kumar, R., Gupta, A. ve Chandra, R., "Characterization and pool boiling heat transfer studies of nanofluids", J. Heat Transfer, Cilt 131, 1-8, 2009.

29. Das, S.K., Narayan, G.P., Anoop, K.B., "Survey on nucleate pool boiling of nanofluids: the effect of particle size relative to roughness", J. Nanoparticle Res., Cilt 10, 1099-1108, 2008.

30. Das, S.K., Putra, N. ve Roetzel, W., "Pool boiling of nano-fluids on horizontal narrow tubes", Int. J. Multiphase Flow, Cilt 29, 1237-1247, 2003.

31. Wenzel, R.N., "Surface roughness and contact angle (letter)", J. Phys. Coll. Chem., Cilt 53, No 9, 1466, 1949.

32. Kim, H.D., Kim, J. ve Kim, M.H., "Experimental studies on CHF characteristics of nano-fluids at pool boiling", Int. J. Multiphase Flow, Cilt 33, 691-706, 2007.

33. Kim, H.D. ve Kim, M.H., "Effect of nanoparticle deposition on capillary wicking that influences the critical heat flux in nanofluids", Applied Physics Letters, Cilt 91, 014104, 2007. 
